\title{
Publisher Correction: Long-haul optical transmission link using low-noise phase-sensitive amplifiers
}

\author{
Samuel L.I. Olsson (10 1,3, Henrik Eliasson¹, Egon Astra ${ }^{2}$, Magnus Karlsson (1) ${ }^{1}$ \& Peter A. Andrekson ${ }^{1}$
}

Correction to: Nature Communications; https://doi.org/10.1038/s41467-018-04956-5; published online: 28 June 2018

The original version of this Article incorrectly listed an affiliation of Samuel L.I. Olsson as 'Thomas Johann Seebeck Department of Electronics, Tallinn University of Technology, Tallinn 19086, Estonia', instead of the correct 'Present address: Nokia Bell Labs, 791 Holmdel Road, Holmdel, NJ 07733, USA'. Similarly, Egon Astra had an incorrect affiliation of 'Present address: Nokia Bell Labs, 791 Holmdel Road, Holmdel, NJ 07733, USA', instead of the correct 'Thomas Johann Seebeck Department of Electronics, Tallinn University of Technology, Tallinn 19086, Estonia'. This has been corrected in both the PDF and HTML versions of the Article.

Published online: 31 July 2018

\footnotetext{
(c) Open Access This article is licensed under a Creative Commons Attribution 4.0 International License, which permits use, sharing, adaptation, distribution and reproduction in any medium or format, as long as you give appropriate credit to the original author(s) and the source, provide a link to the Creative Commons license, and indicate if changes were made. The images or other third party material in this article are included in the article's Creative Commons license, unless indicated otherwise in a credit line to the material. If material is not included in the article's Creative Commons license and your intended use is not permitted by statutory regulation or exceeds the permitted use, you will need to obtain permission directly from the copyright holder. To view a copy of this license, visit http://creativecommons.org/licenses/by/4.0/.
}

(c) The Author(s) 2018

\footnotetext{
${ }^{1}$ Department of Microtechnology and Nanoscience, Chalmers University of Technology, SE-412 96 Gothenburg, Sweden. ${ }^{2}$ Thomas Johann Seebeck Department of Electronics, Tallinn University of Technology, 19086 Tallinn, Estonia. ${ }^{3}$ Present address: Nokia Bell Labs, 791 Holmdel Road, Holmdel, NJ 07733 , USA. The original article can be found online at https://doi.org/10.1038/s41467-018-04956-5. Correspondence and requests for materials should be addressed to S.L.I.O. (email: samuel.olsson@nokia-bell-labs.com)
} 